University of Nebraska - Lincoln

DigitalCommons@University of Nebraska - Lincoln

Faculty Publications, Department of Child, Youth, and Family Studies

Child, Youth, and Family Studies, Department of

2018

Seeing Mathematics Through Different Eyes: An Equitable Approach to Use with Prospective Teachers

\author{
Christa Jackson \\ lowa State University, jacksonc@iastate.edu \\ Cynthia E. Taylor \\ Millersville University of Pennsylvania, cynthia.taylor@millersville.edu \\ Kelley Buchheister \\ University of Nebraska-Lincoln, kbuchheister2@unl.edu
}

Follow this and additional works at: https://digitalcommons.unl.edu/famconfacpub

Part of the Early Childhood Education Commons, Elementary Education Commons, Gender Equity in Education Commons, Science and Mathematics Education Commons, and the Teacher Education and Professional Development Commons

Jackson, Christa; Taylor, Cynthia E.; and Buchheister, Kelley, "Seeing Mathematics Through Different Eyes: An Equitable Approach to Use with Prospective Teachers" (2018). Faculty Publications, Department of Child, Youth, and Family Studies. 316.

https://digitalcommons.unl.edu/famconfacpub/316

This Article is brought to you for free and open access by the Child, Youth, and Family Studies, Department of at DigitalCommons@University of Nebraska - Lincoln. It has been accepted for inclusion in Faculty Publications, Department of Child, Youth, and Family Studies by an authorized administrator of DigitalCommons@University of Nebraska - Lincoln. 


\title{
Seeing Mathematics Through Different Eyes: An Equitable Approach to Use with Prospective Teachers
}

\author{
Christa Jackson, ${ }^{1}$ Cynthia E. Taylor, ${ }^{2}$ and Kelley Buchheister ${ }^{3}$
}

\author{
1 Iowa State University, Ames, IA, USA; jacksonc@iastate.edu \\ 2 Millersville University of Pennsylvania, Millersville, PA, USA; \\ cynthia.taylor@millersville.edu \\ 3 University of Nebraska-Lincoln, Lincoln, NE, USA \\ (Corresponding author); kbuchheister2@unl.edu
}

\begin{abstract}
Teacher educators need to prepare prospective teachers by encouraging them to critically examine their current beliefs about the teaching and learning of mathematics while also providing opportunities for prospective teachers to develop an equity-centered orientation. Attending to these practices in teacher preparation programs may help prospective teachers observe actions that occur in classrooms and determine effective strategies that provide the opportunity to enhance all students' access to high-quality mathematics instruction. As mathematics teacher educators, we must recognize what prospective teachers attend to as they direct their attention to various classroom events and how they relate the events to broader principles of teaching and learning. In this chapter, we investigate what prospective teachers attend to in a classroom vignette of a student who is above grade level in mathematics and exhibits disruptive behavior during instruction. Keeping everything constant in the vignette except the student's race and sex, we examined prospective teachers' responses when the student was an African American
\end{abstract}

\footnotetext{
Published (as Chapter 16) in T. G. Bartell (ed.), Toward Equity and Social Justice in Mathematics Education, Research in Mathematics Education, 2018, pp 263-285. https:// doi.org/10.1007/978-3-319-92907-1_16

Copyright (C) 2018 Springer International Publishing AG. Used by permission.
} 
male, White male, African American female, and White female. By attending specifically to race and sex, we explored whether prospective teachers demonstrated (1) an equity-centered orientation toward mathematics instruction or (2) deficit views of students based on race, sex, or the intersection of the two. Using a constant comparative method, the data were coded and analyzed using the equity noticing framework. The results indicate that prospective teachers are beginning to attend to cultural influences and their responses reveal differences not only between races but also between males and females.

\section{Introduction}

Tell me to what you pay attention and I will tell you who you are.

$$
\text { (José Ortega y Gasset) }
$$

The National Council of Teachers of Mathematics (NCTM) asserts that in order to teach in an equitable manner, teachers and schools must maintain "high expectations and strong support for all students" (2000, p. 11), meaning mathematics teachers must provide opportunities for students to learn challenging mathematics regardless of their students' "personal characteristics, backgrounds, or physical challenges" (p. 12). For the past three decades, mathematics educators have conceptualized what it means to teach mathematics for equity (Gutiérrez, 2002; Gutstein, 2003; Hart, 2003; Matthews, 2005), from gender studies (e.g., Forgasz \& Rivera, 2012) to the considerations of students of color (e.g., Battey, 2013; Diversity in Mathematics Education Center for Learning and Teaching, 2007), socioeconomically disadvantaged students (e.g., Lubienski, 2002), and students who struggle mathematically (e.g., Allsopp, Kyger, \& Lovin, 2007). Only in recent years, though, have mathematics teacher educators documented efforts to prepare prospective teachers (PSTs) to teach mathematics while considering matters of equity (e.g., Bartell, 2010; Freitas, 2008; Wager, 2014).

Although there is an emerging body of research on equitable mathematics instruction (e.g., Leonard \& Martin, 2013; Pinnow \& Chval, 2014; Vomvoridi-Ivanović \& Chval, 2014), there is more to learn about supporting PSTs as they work to implement pedagogical practices that promote and support the mathematical learning of all students 
(Wager, 2014). In fact, "very few teacher education programs have successfully tackled the challenging task of preparing teachers to meet the needs of diverse populations" (Watson, Charner-Laird, Kirkpatrick, Szczesiul, \& Gordon, 2006, p. 396). To address issues of equity and support mathematical learning for all students, it is imperative for teachers to integrate aspects of the students' culture and language within their instruction (NCTM, 2014). Unfortunately, many PSTs do not know how to make these necessary connections, especially with students who are different from their own culture and background (Futrell, Gomez, \& Bedden, 2003; Turner, et al., 2012). Consequently, within the current educational system, students from non-dominant backgrounds are often denied equitable opportunities to learn (Wager, 2014), and maintaining the status quo will only continue to "widen the gap between teachers and children in schools" (Sleeter, 2001, p. 96).

Currently, about $49 \%$ of the US public school population is comprised of culturally and racially diverse groups such as African Americans, Asian-Americans, Latinas, and Native Americans (Hussar \& Bailey, 2016). By 2023, researchers have predicted a "minority-majority flip" for students of color with White students' enrollment declining to $45 \%$ (Hussar \& Bailey, 2016). By 2050, students of color are predicted to represent approximately $62 \%$ of the school-age population (National Center of Educational Statistics, 2010). As the population of public school students continues to become more and more diverse, it is critical that teachers' instructional practices purposefully align with students' funds of knowledge when teaching mathematical concepts because the thoughtful integration of community contexts, resources, and language promotes connections between students' lived experiences and the mathematical content addressed in the classroom setting, thus contributing to meaningful, high-quality instruction (NCTM, 2014).

To further complicate existing disparities in mathematics education, many mathematics teachers and PSTs dismiss issues of equity as relevant factors in the mathematics classroom because they view mathematics as a universal, culture-free subject (Jackson \& Jong, 2017; Rousseau \& Tate, 2003). There is a growing body of mathematics education researchers, however, who understand that mathematics and mathematical knowledge are neither universal nor culturally neutral but are situated in a sociocultural framework (Turner \& 
Drake, 2016; Ukpokodu, 2011). Specifically, Gay (2000) argues that if we "decontextualiz[e] teaching and learning from the ethnicities and cultures of students [it] minimizes the chances that their achievement potential will ever be fully realized" (p. 23). To move PSTs beyond viewing mathematics as a "neutral" subject, work in teacher education programs must purposefully address this point of view by reinforcing how mathematics "reflects particular cultural and sociopolitical contexts, and ways of knowing" (Turner \& Drake, 2016, p. 32). More specifically, mathematics teacher educators must implement pedagogical practices that not only encourage PSTs to reflect upon their perceptions of the subject area, but it is also essential that mathematics teacher educators promote meaningful learning experiences by emphasizing explicit strategies for connecting mathematical concepts to students' lived experiences.

Reducing the opportunity gap in mathematics education is possible by transitioning to an equity-centered paradigm. Teaching mathematics from an equity stance requires teachers to understand that students from diverse backgrounds come into the mathematics classroom with different worldviews. Teachers must be willing to move beyond teaching mathematics from a Eurocentric viewpoint and impart equitable pedagogical practices by building relationships, setting high expectations, and helping students maintain their identities (Ladson-Billings, 1995; Matthews, 2005). According to Irvine (2003), in order for all students to be successful, teachers must make connections "between subject-area content and their students' existing mental schemes, prior knowledge, and cultural perspectives" (p. 47). Furthermore, teachers need to "value the cultural and lived experiences of all children ... [and emphasize] the belief that all children possess strong intellectual capacity and bring a wealth of informal, out-of-school knowledge to the teaching and learning process" (Lemons-Smith, 2008, p. 913). Although mathematics education researchers recognize what needs to be done to teach mathematics to diverse populations of students (e.g., Leonard \& Martin, 2013; Pinnow \& Chval, 2014; Vomvoridi-Ivanović and Chval 2014), mathematics methods courses must better prepare PSTs for their role in creating opportunities that provide students with equitable access for learning highquality mathematics (Aguirre, et al., 2012). Hand (2012) documents the importance of the relationship between teachers' instructional 
practice and their dispositions toward equity. Therefore, it is imperative for mathematics teacher educators to prepare PSTs by promoting an equity-centered paradigm, which begins by implementing activities in mathematics methods courses that encourage PSTs to critically examine their current beliefs supplemented by discussions that explicitly address the elements of teaching mathematics through an equitable lens.

The purpose of this chapter is to examine what PSTs attend to in a classroom vignette of a student who is above grade level in mathematics and exhibits disruptive behavior during instruction. More specifically, the research question underlying this study is what do PSTs notice when the student in the vignette is an African American male, White male, African American female, and White female? By attending specifically to race and gender in this study, we can explore whether PSTs demonstrate (a) an equity-centered orientation toward mathematics instruction or (b) deficit views of students based on race, gender, or the intersection of the two. The focus on what PSTs attend to in classroom situations and a purposeful analysis of how PSTs interpret teachers' actions provides a mechanism that contributes to the field in two major ways. First, the empirical data adds to the research by identifying what is most salient to PSTs in the classroom and how what PSTs attend to intersects with the equity-centered paradigm. Secondly, with this knowledge, mathematics teacher educators can begin valuable work to disrupt existing inequities in students' learning experiences by opening critical dialogue that highlights how our perceptions and actions can either enhance or hinder students' access to high-quality, rigorous mathematics instruction.

\section{Equity Noticing Framework}

Gutiérrez (2007, 2009, 2013) argues that equity includes four dimensions: access (i.e., resources that provide students an opportunity to learn rigorous mathematics), achievement (i.e., students' outcomes, students' scores on standardized and non-standardized mathematics assessments, students' participation), identity (i.e., drawing on students' cultural frame to see themselves and the broader society in mathematics), and power (i.e., social transformations such as voice, 


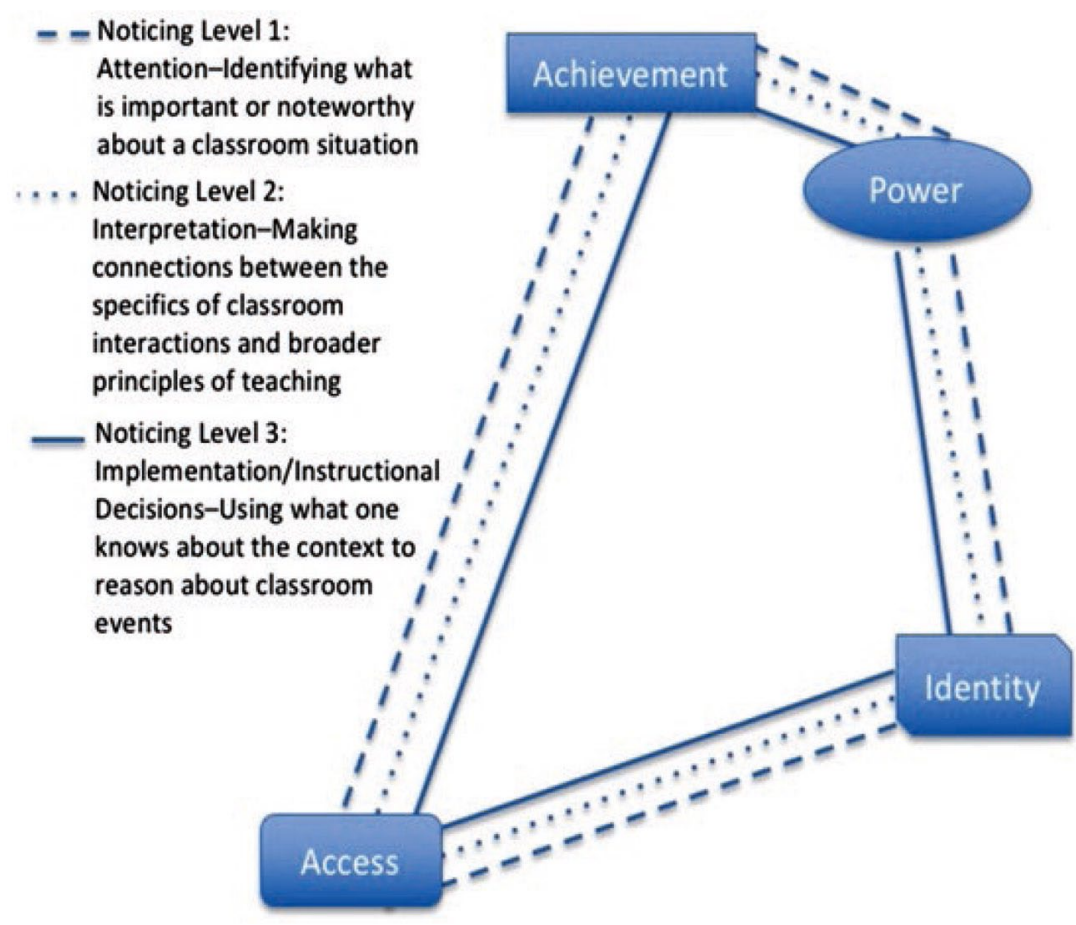

Fig. 1 The equity noticing framework

who is being privileged, and using mathematics to read and change the world). To examine how PSTs perceive classroom situations and identify what they notice - or attend to - during the teaching and learning process, we integrated Gutiérrez's (2013) four dimensions of equity within van Es and Sherin's (2002) three main components of noticing - attention, interpretation, and implementation/instructional decisions (see Fig. 1). The structure of the Equity Noticing Framework provides a lens for researchers to investigate how each dimension of equity is or is not evident within each level of noticing.

Classroom episodes are complex; it is inevitable that individuals choose, consciously or subconsciously, what they notice, or attend to, and use the interpretations of these events to make instructional decisions (Sherin, Russ, Sherin, \& Colestock, 2009). Teachers may attend to equitable issues in the classroom as a process or as a product (Gutiérrez, 2002; Martin, 2003; Rousseau \& Tate, 2003). Seeing equity as a process means treating all students equally, without regard to race, ethnicity, or economic background. On the other hand, seeing 
equity as a product means differentiating instruction based upon students' needs; implementing equitable approaches that are respectful of students' ethnic, racial, and economic background; and promoting equal learning outcomes. According to Gutiérrez (2013), when teachers have equitable practices, the power of predicting students' outcomes (e.g., participation, achievement, ability) is not based on students' background, race, class, or gender but in how students are positioned and the power they are given in the mathematics classroom. In other words, "[students are] both greatly influenced by and greatly influence the taken-for-granted rules and institutions in mathematics education" (Gutiérrez, 2013, p. 46). This approach to teacher education emphasizes the importance of being responsive to students from diverse backgrounds by developing a mindset in teachers that attends to preK-12 students' cultural capital (Averill et al., 2009; McCulloch, Marshall, \& DeCuir-Gunby, 2009).

In the classroom, many things happen simultaneously, and the teacher must decide what deserves immediate consideration (van Es \& Sherin, 2006). Noticing is a culturally shaped perception, which may include preferences and biases. Ball (2011) claims the noticing required in teaching is highly specialized because teachers must be attuned to notice things such as existing knowledge, potential difficulties, and learning trajectories, as well as how cultural capital contributes to students' interpretations. Therefore, it is vital that teachers acknowledge and effectively address how cultural experiences influence their perceptions and interpretations of students and classroom events. van Es and Sherin (2002) argue there are three main components of noticing: (1) identifying what is important about a situation (attention), (2) making connections between the specifics of classroom interactions and the broader principles of teaching and learning they represent (interpretation), and (3) using what one knows about the context to reason about classroom events (implementation/instructional decisions).

The first level of noticing (attention) involves the ability to focus one's attention on what is significant. In other words, teachers decide what deserves immediate consideration (van Es \& Sherin, 2006) while simultaneously regulating what dimensions of equity - access, achievement, identity, power - are valued in their practice. Although what is noticed in a classroom episode might not be understood as an 
explicitly reasoned choice, the second level of noticing (interpretation) also underlines the role of active reflection, which involves using knowledge of one's context to reason about events that occur. During the reflection process, the teacher makes connections between specific events and the broader principles they represent. For example, when encouraged to extrapolate from the specific to the general, teachers form connections between the particular instances they observed and the broader pedagogical issues such events may represent (van Es \& Sherin, 2010). Consequently, it is vital to examine how PSTs perceive students and interpret classroom events with respect to the four dimensions of equity (i.e., access, achievement, identity, and power).

The third level of noticing (implementation/instructional decisions) includes teachers using knowledge about their students, curriculum, and school context to reason about events that occur while simultaneously attending to the four dimensions of equity as teachers make instructional decisions. For example, when teachers provide students with opportunities to engage in high-quality, appropriate tasks, students are given access to learn rigorous mathematics and feel a sense of empowerment as they develop the strategies and skills necessary to use mathematics to change the world. Moreover, students' identities are shaped by agentive opportunities to participate. It is the role of the teacher to develop experiences and guide discussions so all students, particularly those from non-dominant backgrounds, have opportunities to develop strong mathematical identities. Conducting an empirical study that uses the equity noticing framework to focus on what PSTs attend to in classroom situations can add to this research and is critical to disrupt existing inequities in students' learning experiences.

\section{Method}

In this chapter, we describe an activity used in our elementary mathematics methods course that was designed to encourage PSTs to face existing (and often hidden) bias in order to alter unproductive beliefs and consequently broaden their ways of seeing. We view this as an essential activity to help PSTs (a) develop an awareness of equity, (b) define what equity means in classroom instruction, and (c) 
implement equity practices within the mathematics classroom. We examined what PSTs noticed about students' mathematical thinking and its relation to culture, home, and community.

PSTs from four different universities in the southeast, Midwest, and northeast sections of the United States participated in the study. All participants were within 1 year of student teaching. The demographics of the PSTs reflected demographic patterns of elementary education majors at our universities and included 92.2\% White females, $3.7 \%$ White males, $0.3 \%$ Latino, 1.4\% Asian females, and 2.7\% African American females. These demographics continue to support the existing data that a less diverse population of PSTs is facing an everincreasing diverse population of students in our public school systems (Hussar \& Bailey, 2016).

\section{The Vignette}

To access PSTs' thoughts and ideas on issues related to equity in the mathematics classroom, we used classroom vignettes to identify what they noticed. Each vignette represented a different scenario that potentially challenged students' equitable access to high-quality mathematics. The five authentic topics focused on the following teachers: (a) one who exhibits gender bias for class participation, (b) one with preconceived biases that cause him/her to withdraw from students who are from different backgrounds than himself/herself, (c) an instructor who does not take time to develop relationships with his/her racially diverse students, (d) one who recommends a new English learner with limited English proficiency for special education services without adequately assessing the student's content knowledge, and (e) a teacher who is frustrated with a student who is above grade level in mathematics and exhibits disruptive classroom behavior. For this chapter, we describe what the PSTs attended to in their responses to the vignette that involved Eric, an African American male, who was above grade level in mathematics but was disruptive during mathematics instruction (see Fig. 2) because the case provided the most information regarding how PSTs attended to students' actions and mathematical thinking and its relation to culture, home, and community. 


\begin{abstract}
Case: Eric
Eric, an African American third grader, is a good-looking nine-year old boy who was retained in first grade. He is below grade level in reading and language, but above grade level in mathematics. He has been removed from his home because of abuse and is being raised by a caring grandmother. During mathematics lessons, Eric harasses the other children. He closes their books while they are working, knocks their books and pencils off their desks, writes on their papers, and crumples up their work. He does his best to disrupt the lessons by making gestures and deliberately making noises. Ms. Maben, his teacher, is frustrated.

Reflection Questions:

1. If you were the teacher in this situation, how would you respond?

2. What are the implications for elementary teachers?

3. Additional comments or thoughts?
\end{abstract}

Fig. 2 Vignette of Eric and corresponding reflection questions

After conducting an initial analysis of PSTs' responses on the Eric vignette, we wondered if we would have the same results if Eric was White and if Eric was changed to a female, Erica, who was White or African American. Consequently, we administered a modified version of the Eric vignette to our students the following semester. In the modified version, we included an example of the student's strategy for solving a mathematics problem to further emphasize and provide PSTs an opportunity to examine a student's mathematical thinking, and we varied the demographics of the student by race (African American or White) and sex (male [Eric] or female [Erica]) while keeping all other characteristics and descriptions constant (see Fig. 3). We noticed a dichotomy of what the PSTs perceived between Eric[a]'s mathematical understanding and his/her disruptive behavior during a mathematics lesson.

\title{
Data Collection and Data Analysis
}

To access the PSTs' thoughts and ideas on issues related to equity in the mathematics classroom, we used classroom vignettes that represented situations that potentially challenged students' equitable access to high-quality mathematics.

Data Collection The PSTs $(n=180)$ were asked to respond to the five vignettes described earlier that focused on authentic topics for 


\section{Case 3: Eric}

Eric, an African American third grader, is a good-looking nine-year old boy who was retained in first grade. He is below grade level in reading and language, but above grade level in mathematics. He has been removed from his home because of abuse and is being raised by a caring grandmother. During mathematics lessons, Eric harasses the other children. He closes their books while they are working, knocks their books and pencils off their desks, writes on their papers, and crumples up their work. He does his best to disrupt the lessons by making gestures and deliberately making noises. When he solves mathematics problems, he always solves them a different way than how Ms. Maben, his teacher, taught. For example, Eric was given the following problem: Ricky has 354 markers. He gave 179 to Tommy. How many markers does Ricky have? To solve the problem Eric did the following:

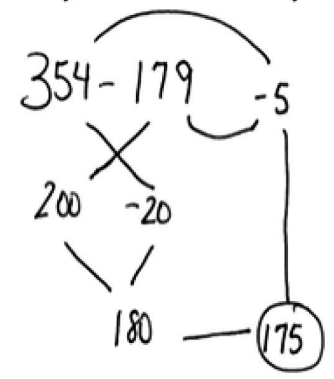

Ms. Maben is extremely frustrated with Eric.

1. What are your thoughts on the above scenario?

2. If you were the teacher in this situation, how would you respond?

3. What was Eric's mathematical thinking?

4. Additional comments or thoughts?

Fig. 3 Modified Eric[a] vignette

pedagogical discussions related to teachers facing equity issues. To help ensure all PSTs fully participated in the class discussion, each PST independently read and responded to corresponding reflection questions for each vignette. Using a modified version of "jigsaw," a cooperative learning structure (McGuire, 2006), the PSTs were divided into five groups, where each group was randomly assigned a specific vignette and asked to discuss their responses, which were audio-recorded and transcribed. The PSTs recorded their thoughts to the guiding questions that accompanied their case on chart paper, and an expert was selected from each small group to share their results with other members in the class. Everyone from each group, except the expert, rotated from vignette to vignette and listened to the "expert" 
report the group's analysis of the situation before the PSTs shared their individual thoughts pertaining to the events in the vignette. At the conclusion of the discussion, the PSTs recorded their thoughts and ideas on post-it notes that were placed on chart paper. Once the PSTs finished rotating to each of the other four groups, they returned to their original group where the expert shared what he/she learned from the discussions with the other groups. Finally, the PSTs shared their thoughts and ideas on each case within a large group discussion.

In order to accurately draw conclusions on whether the PSTs' responses were based on Eric's race (i.e., African American), we modified the vignette and randomly assigned it to our PSTs. The PSTs ( $n$ $=114)$ at three universities were randomly assigned three vignettes (i.e., White Eric, White Erica, African American Erica) as comparison cases to the vignette with African American Eric, which was previously administered. The PSTs individually responded to the prompts and discussed their responses in a small group setting with those who were assigned the same student - White Eric, White Erica, or African American Erica. The PSTs recorded their thoughts and ideas that were most salient on a chart paper, which was shared with the class. During a whole group discussion, the PSTs identified the similarities and noted key differences within and across the responses to each vignette. Thus, the data collected for this study included PSTs' individual responses to the prompts, collective chart paper responses, and class discussion.

Data Analysis To analyze the data for evidence of the three levels of noticing across the four dimensions of equity, we (i.e., each author) independently coded the data and wrote analytical memos. We met throughout the process to verify that the coding was consistent and to resolve any differences, first through refining the code definitions and then through discussions of the coding until agreement was reached (see Table 1 for coding dictionary). We then quantified the number of "referring responses" (total $n=632$ ), which represented the number of references the PSTs made for each coding category (i.e., noticing level 1: attention/access). 
Table 1 Coding dictionary. All of the codes in each cell are from the data except noticing level $1 /$ access. There was not any data for this cell, so we included a representative code.

\begin{tabular}{|c|c|c|c|c|}
\hline & Access & Achievement & Identity & Power \\
\hline $\begin{array}{l}\text { Noticing level } \\
\text { 1: attention }\end{array}$ & \begin{tabular}{|l|} 
The task was to \\
find the \\
difference \\
between 179 \\
and 354
\end{tabular} & $\begin{array}{l}\text { "He is above grade } \\
\text { level in } \\
\text { mathematics." "The } \\
\text { child has the correct } \\
\text { answer" }\end{array}$ & $\begin{array}{l}\text { "Why does it } \\
\text { matter } \\
\text { specifically that } \\
\text { he is white and } \\
\text { good-looking?" }\end{array}$ & $\begin{array}{l}\text { "Erica harasses } \\
\text { the other children" }\end{array}$ \\
\hline $\begin{array}{l}\text { Noticing level } \\
\text { 2: interpretation }\end{array}$ & \begin{tabular}{|l|} 
"If he is truly \\
above grade \\
level in \\
mathematics, \\
and he is acting \\
out during the \\
math lessons, \\
she needs to \\
give him harder \\
assignments"
\end{tabular} & $\begin{array}{l}\text { "I personally think } \\
\text { that her way of } \\
\text { thinking is crazy yet } \\
\text { intriguing. She } \\
\text { subtracted each } \\
\text { place value and then } \\
\text { took the remaining } \\
\text { numbers and } \\
\text { subtracted those. } \\
\text { Erica took } \\
300-100 \text { to get the } \\
200 \text {; she took } \\
50-70 \text { to get }-20 \text {; } \\
\text { and she took } 4-9 \\
\text { to get }-5 \text {. After } \\
\text { those steps, she took } \\
\text { the } 200-20 \text { to get } \\
180 \text { and then } \\
180-5 \text { to get a } \\
\text { final answer of } 175 \text { " }\end{array}$ & \begin{tabular}{|l|} 
"Erica has a \\
mathematical \\
mind and is \\
capable of \\
expanding her \\
knowledge much \\
further at this \\
time." "Erica has \\
some serious \\
problems. It \\
sounds like it \\
starts at home \\
and continues \\
over to school"
\end{tabular} & $\begin{array}{l}\text { "If Erica is held } \\
\text { accountable for } \\
\text { new and more } \\
\text { challenging } \\
\text { learning, she may } \\
\text { sustain from } \\
\text { causing more } \\
\text { trouble in the } \\
\text { classroom." "This } \\
\text { took me about } \\
10 \text { min to figure } \\
\text { out, which is why } \\
\text { it should not be } \\
\text { recommended for } \\
\text { students to use" }\end{array}$ \\
\hline $\begin{array}{l}\text { Noticing level } \\
\text { 3: } \\
\text { implementation/ } \\
\text { instructional } \\
\text { decisions }\end{array}$ & $\begin{array}{l}\text { "I would try to } \\
\text { provide work } \\
\text { for Erica that } \\
\text { provides a } \\
\text { challenge for } \\
\text { her. I would } \\
\text { also see if there } \\
\text { was a more } \\
\text { advanced math } \\
\text { class that she } \\
\text { could switch } \\
\text { to" }\end{array}$ & $\begin{array}{l}\text { "I would make sure } \\
\text { I am not attacking } \\
\text { him but point out } \\
\text { that his disruption is } \\
\text { robbing his } \\
\text { classmates of a } \\
\text { chance to learn, as } \\
\text { well as himself." "I } \\
\text { would put Eric in a } \\
\text { place by himself, so } \\
\text { he cannot harass } \\
\text { anyone" }\end{array}$ & \begin{tabular}{|l|} 
"I would have \\
Erica be my \\
special math \\
scientist. I would \\
have her help \\
students when \\
she is finished. \\
She can be like \\
my STA (student \\
teacher \\
assistant)"
\end{tabular} & $\begin{array}{l}\text { "If I wanted her to } \\
\text { do the problem } \\
\text { the way I taught } \\
\text { it, then I would sit } \\
\text { down with her and } \\
\text { ask her how she } \\
\text { solved it and then } \\
\text { tell her that I } \\
\text { would like it to be } \\
\text { done the way I } \\
\text { taught it" }\end{array}$ \\
\hline
\end{tabular}

\section{Results}

In this study, we examined what PSTs noticed and attended to when the student in the classroom vignette was an African American male, White male, African American female, and White female. In this section, we discuss what the PSTs attended to within each of the three 
Table 2 Prospective teachers' level of noticing within the dimensions of equity. Purple percentages indicate percent of the dimensions of equity, while the blue percentages indicate the percent of the levels of noticing.

\begin{tabular}{|l|l|l|l|l|l|}
\hline & Access & Achievement & Identity & Power & TOTAL \\
\hline Noticing level & 0 & 40 & 1 & 11 & $\mathbf{5 2}$ \\
1: attention & $0 \%$ & $19.0 \%$ & $0.9 \%$ & $5.3 \%$ & $8.2 \%$ \\
& $0 \%$ & $76.9 \%$ & $1.9 \%$ & $21.2 \%$ & \\
\hline Noticing level & 21 & 119 & 26 & 83 & $\mathbf{2 4 9}$ \\
2: interpretation & $20.2 \%$ & $56.7 \%$ & $23.2 \%$ & $40.3 \%$ & $39.4 \%$ \\
& $8.4 \%$ & $47.8 \%$ & $10.4 \%$ & $33.3 \%$ & \\
\hline Noticing level & 83 & 51 & 85 & 112 & $\mathbf{3 3 1}$ \\
$\begin{array}{l}\text { 3: } \\
\text { implementation/ } \\
\text { instructional } \\
\text { decisions }\end{array}$ & $79.8 \%$ & $24.3 \%$ & $75.9 \%$ & $54.4 \%$ & $52.4 \%$ \\
\hline TOTAL & & $15.4 \%$ & $25.7 \%$ & $33.8 \%$ & \\
& $\mathbf{1 0 4}$ & $\mathbf{2 1 0}$ & & & \\
\hline
\end{tabular}

levels of noticing and across the four dimensions of equity. In addition, we not only identify what PSTs noticed in relation to Eric[a], but we also describe how these findings were similar or varied depending on the race and sex of the student.

\section{Overview}

When looking across the data, the findings demonstrated how the PSTs' responses corresponded to the three levels of noticing and how the percentage of total responses focused on each dimension of equity (see Table 2).

The first level of noticing - attention - had the fewest references, with only $8.2 \%$ of the responses, while about $39 \%$ of the PSTs' responses were in level 2 noticing - interpretation. The majority of the responses from the PSTs focused on their instructional decisions, with over half of the references corresponding to level 3 noticing - implementation. While these data are interesting, it is not surprising given that one of the prompts specifically asked the PSTs "what would you do if you were Ms. Maben?" Consequently, these results also serve as a continued reminder that the tasks teacher educators provide PSTs 
- and the questions that are posed - may implicitly, or purposefully, guide what PSTs attend to and subsequently learn.

Across the three levels of noticing, the majority of the references corresponded to achievement (33.2\%) and power (32.6\%). This result implies that PSTs are focused on student outcomes, such as the correctness of a student's mathematical response, as well as the opportunities for, and the hindrances to, classroom participation. Moreover, these data suggest PSTs seem to view the role of the classroom teacher as one who maintains order and control, which often reflects privilege, and in some cases stifles the student's voice in the classroom. Throughout the total responses, the PSTs' attention to developing tasks (access) and reflecting on drawing upon Eric[a]'s identity was less prominent.

In the subsequent sections, we provide a detailed explanation of each level of noticing and discuss how the four dimensions of equity are addressed. Specifically, we describe the disparities that emerged across race and sex to answer the research question underlying this study: What do prospective teachers notice and attend to when the student in the vignette is an African American male, White male, African American female, and White female?

\section{Noticing Level 1: Attention - What Is Noteworthy?}

The majority of references $(76.9 \%)$ in the first level of noticing are related to achievement (see Table 3), which seems to imply that PSTs mainly focused on outcomes and answers. While references to power within this level occurred less often (21.2\%), the responses were generally related to classroom management and behavioral issues (e.g., "Erica harasses the other children"). And, of the 52 total references at noticing level 1, only one of the PSTs' responses corresponded to identity (1.9\%), while none referenced access.

Achievement Of the 40 references that corresponded to achievement, 37 stated either Eric[a] was above grade level or had the correct answer. Furthermore, only in the responses for Erica did the PSTs indicate the student had the correct answer, whereas when PSTs discussed retention and limited reading skills, these responses were only 
Table 3 Noticing level 1: attention - what is noteworthy? Purple percentages indicate percent of the dimensions of equity, while the red percentages indicate the percent of the student's demographics.

\begin{tabular}{|c|c|c|c|c|c|c|}
\hline & Access & Achievement & Identity & Power & TOTAL & TOTAL \\
\hline $\begin{array}{l}\text { African } \\
\text { American } \\
\text { ERIC }\end{array}$ & $\begin{array}{l}0 \\
0 \% \\
0 \%\end{array}$ & $\begin{array}{l}9 \\
22.5 \% \\
81.8 \%\end{array}$ & $\begin{array}{l}0 \\
0 \% \\
0 \%\end{array}$ & $\begin{array}{l}2 \\
18.2 \% \\
18.2 \%\end{array}$ & $\begin{array}{l}11 \\
21.2 \%\end{array}$ & \multirow{2}{*}{$\begin{array}{l}39 \\
75 \%\end{array}$} \\
\hline $\begin{array}{l}\text { African } \\
\text { American } \\
\text { ERICA }\end{array}$ & $\begin{array}{l}0 \\
0 \% \\
0 \%\end{array}$ & $\begin{array}{l}19 \\
47.5 \% \\
67.9 \%\end{array}$ & $\begin{array}{l}0 \\
0 \% \\
0 \%\end{array}$ & $\begin{array}{l}9 \\
81.8 \% \\
32.1 \%\end{array}$ & $\begin{array}{l}28 \\
53.8 \%\end{array}$ & \\
\hline $\begin{array}{l}\text { White } \\
\text { ERIC }\end{array}$ & $\begin{array}{l}0 \\
0 \% \\
0 \%\end{array}$ & $\begin{array}{l}2 \\
5 \% \\
66.7 \%\end{array}$ & $\begin{array}{l}1 \\
100 \% \\
33.3 \%\end{array}$ & $\begin{array}{l}0 \\
0 \% \\
0 \%\end{array}$ & $\begin{array}{l}3 \\
5.8 \%\end{array}$ & \multirow{2}{*}{$\begin{array}{l}13 \\
25 \%\end{array}$} \\
\hline $\begin{array}{l}\text { White } \\
\text { ERICA }\end{array}$ & $\begin{array}{l}0 \\
0 \% \\
0 \%\end{array}$ & $\begin{array}{l}10 \\
25 \% \\
100 \%\end{array}$ & $\begin{array}{l}0 \\
0 \% \\
0 \%\end{array}$ & $\begin{array}{l}0 \\
0 \% \\
0 \%\end{array}$ & $\begin{array}{l}10 \\
19.2 \%\end{array}$ & \\
\hline TOTAL & $\begin{array}{l}0 \\
0 \%\end{array}$ & $\begin{array}{l}40 \\
76.9 \%\end{array}$ & 1 & $\begin{array}{l}11 \\
21.2 \%\end{array}$ & 52 & \\
\hline
\end{tabular}

in reference to African American Eric. Moreover, when closely examining discrepancies between races, $70 \%$ of the PSTs' references in achievement were for the African American students. While this may seem arbitrary, it leads us to question if this finding implies that PSTs are more inclined to notice and attend to achievement for African American students when they were identified as high achievers in mathematics. It appears that PSTs expect mathematical success for White males ( $5 \%$ of the achievement responses); therefore, the fact a White male was above grade level in mathematics seems "normal" to PSTs, whereas the success was more "noteworthy" for all of the other students.

Identity The only identity reference at this level was for White Eric, and the PST stated, "Why does it matter that he is white and goodlooking?” By asking this question, the PST dismisses the socialization of race and the treatment of students based on looks. It has been documented that nicer-looking people are treated more favorably than those who are not (Olson \& Marshuetz, 2005), and often the attractive student's misbehaviors are overlooked, or they are given a lighter consequence. 
Table 4 Noticing level 2: interpretation - connections to principles of teaching and learning. Purple percentages indicate percent of the dimensions of equity, while the red percentages indicate the percent of the student's demographics

\begin{tabular}{|c|c|c|c|c|c|c|}
\hline & Access & Achievement & Identity & Power & \begin{tabular}{|l|} 
TOTAL \\
\end{tabular} & TOTAL \\
\hline $\begin{array}{l}\text { African } \\
\text { American } \\
\text { ERIC }\end{array}$ & $\begin{array}{l}5 \\
23.8 \% \\
7.1 \%\end{array}$ & $\begin{array}{l}24 \\
20.2 \% \\
34.3 \%\end{array}$ & $\begin{array}{l}7 \\
26.9 \% \\
10 \%\end{array}$ & $\begin{array}{l}34 \\
41 \% \\
48.6 \%\end{array}$ & $\begin{array}{l}70 \\
28.1 \%\end{array}$ & \multirow{2}{*}{$\begin{array}{l}178 \\
71.5 \%\end{array}$} \\
\hline $\begin{array}{l}\text { African } \\
\text { American } \\
\text { ERICA }\end{array}$ & $\begin{array}{l}11 \\
52.4 \% \\
10.2 \%\end{array}$ & $\begin{array}{l}58 \\
48.7 \% \\
53.7 \%\end{array}$ & $\begin{array}{l}15 \\
57.7 \% \\
13.9 \%\end{array}$ & $\begin{array}{l}24 \\
28.9 \% \\
22.2 \%\end{array}$ & $\begin{array}{l}108 \\
43.4 \%\end{array}$ & \\
\hline $\begin{array}{l}\text { White } \\
\text { ERIC }\end{array}$ & $\begin{array}{l}2 \\
9.5 \% \\
8.7 \%\end{array}$ & $\begin{array}{l}8 \\
6.7 \% \\
34.8 \%\end{array}$ & $\begin{array}{l}2 \\
7.7 \% \\
8.7 \%\end{array}$ & $\begin{array}{l}11 \\
13.3 \% \\
47.8 \%\end{array}$ & $\begin{array}{l}23 \\
9.2 \%\end{array}$ & \multirow{2}{*}{$\begin{array}{l}71 \\
28.5 \%\end{array}$} \\
\hline $\begin{array}{l}\text { White } \\
\text { ERICA }\end{array}$ & $\begin{array}{l}3 \\
14.3 \% \\
6.3 \%\end{array}$ & $\begin{array}{l}29 \\
24.4 \% \\
60.4 \%\end{array}$ & $\begin{array}{l}2 \\
7.7 \% \\
4.2 \%\end{array}$ & $\begin{array}{l}14 \\
16.9 \% \\
29.2 \%\end{array}$ & $\begin{array}{l}48 \\
19.3 \%\end{array}$ & \\
\hline TOTAL & $\begin{array}{l}21 \\
8.4 \% \\
\end{array}$ & $\begin{array}{l}119 \\
47.8 \%\end{array}$ & $\begin{array}{l}26 \\
10.4 \%\end{array}$ & $\begin{array}{l}83 \\
33.3 \% \\
\end{array}$ & 249 & \\
\hline
\end{tabular}

Power References attending to privilege, position, control, and voice comprised $\mathbf{2 1 . 2} \%$ of the responses. Examining the disaggregated responses more closely reveals that all of the power references were for African American Eric[a]. In these responses, the PSTs attended to and recorded the description that the student was harassing other students or was disruptive by throwing paper and closing books.

\section{Noticing Level 2: Interpretation - Connections to Principles of Teaching and Learning}

At the noticing level 2 - interpretation - more than $70 \%$ of the references were for the African American students (see Table 4), and within each race the number of references for females was about twice as much as the males. Females also dominated the responses in achievement with $73.1 \%$ of the references. In addition, within this level of noticing, the references within achievement (47.8\%) were the highest, followed by power (33.3\%). This result implies PSTs were mainly focusing their responses on outcomes and interpreting the vignette through the lens of a dominant voice or control in the classroom, particularly for African American students. 
Access Within access, 95.2\% of the references indicated that the PSTs perceived the student was not challenged, and $75 \%$ of these responses were in reference to the African American students. For example, one PST noted, "It sounds like [African American] Eric is not being pushed hard enough and there might be an issue with the expectations of him." Similarly, another PST stated, "I believe the reason he [White Eric] is being disruptive is because the math lessons are probably too simple or easy for him." While the responses for Eric focused on why he was disruptive, responses centering on Ms. Maben's frustration, which inhibits student's access to rigorous mathematical tasks, were predominantly for the African American students.

Achievement Approximately 30\% of the PSTs responses stated Eric[a] was bored, which may hinder the student's participation, as one of the reasons why he/she was causing disruptions. For example, a PST suggested, "[African American] Eric is very smart in the subject of mathematics so acting out may be caused by boredom." Another PST offered, "[African American Erica] is bored and that is why she only bothers other students during math class."

In relation to Eric[a]'s mathematical thinking, some of the PSTs understood the student's thinking and articulated how the student solved the problem. For example, a PST commented [African American] Erica used the "place value method" to solve the problem. The PST went on to explain the student's understanding:

Subtracting 5 from 179 give 174 making it easier to compare to 354 . Giving a -5 . Looking at the ones \& tens place it is easy to see that -20 is the difference between 54 and 74 . Next comparing the hundreds place you can see that $300-$ 100 is 200 . Erica is left with $200,-20$, and -5 which once added [is] 175 .

Unfortunately, $45.9 \%$ of the PSTs' references revealed they did not understand the student's mathematical strategy for solving the subtraction problem. A PST articulated,

I am unsure how she arrived at the solution. It is correct which also confuses me because I am uncertain how she got 
to the right answer. I understand how she got the $(-5)$ but then I am unclear where the 200 and -20 come from.

Another PST stated, “I can't tell what her logic is with the math. I can't tell the beginning steps of her system." It is interesting to note that some of the PSTs interpreted African American Erica's mathematical thinking as an attempt to avoid the mathematics. None of the responses for African American Eric related to interpreting his mathematical thinking. Instead, the PSTs suggested African American Eric had a learning disability in mathematics and should be held back a grade level.

Identity Over $80 \%$ of the references for identity were for the African American students with a considerable focus on the difficult home life. For African American Erica, 11 of the 20 responses addressed her difficult home situation. For example, "She [African American Erica] has a lot of emotions and is looking for a way to solve them." On the other hand, it is interesting to note that two references identified African American Erica as one with a "mathematical mind." Moreover, out of the three references regarding the size of the student, two indicated African American Eric would be "much bigger" than the other students and interpreted his identity as that of a bully. For example, one PST stated, "I would talk to him about being a bully to other students."

Power About 70\% of the references in power corresponded to the African American students. Moreover, these responses were more negative when compared to the responses for the White students. For example, a PST explained, "[African American] Eric would be a great student that could really benefit from being held back this year so that he could grow and learn to practice age appropriate behaviors and gain the reading skills he needs to move on." This PST's comment completely disregarded the fact that Eric was above grade level in mathematics. For White Eric, a PST commented, "Once he is engaged in the lessons, the disruptive behavior will stop.”

The PSTs (45.7\% of the referring responses) primarily focused on the need for the student to have attention and or control in the classroom. One PST stated, "I think [White] Erica is doing extra steps and going around the problem for extra attention. She knows the teacher 
Table 5 Noticing level 3: implementation actions such as instructional or pedagogical strategies. Purple percentages indicate percent of the dimensions of equity, while the red percentages indicate the percent of the student's demographics

\begin{tabular}{|c|c|c|c|c|c|c|}
\hline & Access & Achievement & Identity & Power & TOTAL & TOTAL \\
\hline African & 39 & 22 & 44 & 42 & \multirow{3}{*}{$\begin{array}{l}147 \\
44.4 \%\end{array}$} & \multirow{6}{*}{$\begin{array}{l}251 \\
75.8 \%\end{array}$} \\
\hline American & $47 \%$ & $43.1 \%$ & $51.8 \%$ & $37.5 \%$ & & \\
\hline ERIC & $26.5 \%$ & $15 \%$ & $30 \%$ & $28.6 \%$ & & \\
\hline African & 30 & 17 & 22 & 35 & \multirow{3}{*}{$\begin{array}{l}104 \\
31.4 \%\end{array}$} & \\
\hline American & $36.1 \%$ & $33.3 \%$ & $25.9 \%$ & $31.3 \%$ & & \\
\hline ERICA & $28.8 \%$ & $16.3 \%$ & $21.2 \%$ & $33.7 \%$ & & \\
\hline White & 9 & 6 & 6 & 14 & \multirow{3}{*}{$\begin{array}{l}35 \\
10.6 \%\end{array}$} & \multirow{6}{*}{$\begin{array}{l}80 \\
24.2 \%\end{array}$} \\
\hline ERIC & $10.8 \%$ & $11.8 \%$ & & $12.5 \%$ & & \\
\hline & $25.7 \%$ & $17.1 \%$ & $17.1 \%$ & $40 \%$ & & \\
\hline White & 5 & 6 & 13 & 21 & \multirow{3}{*}{$\begin{array}{l}45 \\
13.6 \%\end{array}$} & \\
\hline ERICA & $6 \%$ & $11.8 \%$ & $15.3 \%$ & $18.8 \%$ & & \\
\hline & $11.1 \%$ & $13.3 \%$ & $28.9 \%$ & $46.7 \%$ & & \\
\hline TOTAL & $\begin{array}{l}83 \\
25.1 \%\end{array}$ & $\begin{array}{l}51 \\
15.4 \%\end{array}$ & $\begin{array}{l}85 \\
25.7 \%\end{array}$ & $\begin{array}{l}112 \\
33.8 \%\end{array}$ & \multicolumn{2}{|l|}{331} \\
\hline
\end{tabular}

is going to spend time talking to her if she does the problem wrong." In addition, the PSTs only indicated that African American Erica should be "held responsible for the actions."

It was reassuring, however, that 14 responses explicitly identified the need to empower or bring voice to Eric[a] by making adjustments to Ms. Maben's teaching. One PST mentioned, "there could be judgments about his [African American Eric] race that are unfair, just because he is being disruptive." While there were no explicit implications for instruction listed, these highlight that a small number of PSTs are beginning to interpret the situation as an area that can be altered by conscious pedagogical actions that address the needs of the students.

\section{Noticing Level 3: Implementation Actions Such as Instructional or Pedagogical Strategies}

The third level of noticing had the largest number (331/632, or $52.4 \%$ ) of total references (see Table 5). In this level, the PSTs focused mainly on actions that would reflect power, control, and voice in the classroom (33.8\%) and emphasis on pedagogical decisions that correspond to identity (25.7\%) and access (25.1\%). 
Access Instructional actions that corresponded to access were those that related to tasks, resources, or tools that provide Eric[a] with opportunities to learn challenging and rigorous mathematics. Some of these actions benefited and challenged the student, while others potentially inhibited the student's access to high-quality and appropriately challenging mathematics. One PST stated the job of the classroom teacher is to "make sure that a student is being challenged and engaged on a level that is appropriate for them." Noticing and supporting the need to select appropriately challenging tasks for Eric[a] indicated that the PSTs did recognize increasing rigor, and stimulating the student's thinking was a viable strategy to quell the issues related to behavior. In fact, one PST wrote, "I would provide [African American Erica] with more challenging math concepts to deepen her thinking, hoping that will curve some of the disruptions.” Another PST stated, "[African American] Eric needs to have access to more difficult problems to deepen his thinking."

While some PSTs stated they would give the student challenging problems, other PSTs commented they would give Eric more work, essentially "busy work." Responses referencing "busy work" seemed to overlook the possibility that Eric was not receiving appropriate assignments, and instead of reflecting on and exploring opportunities to stimulate the student's thinking through high-quality tasks that appropriately and effectively challenged Eric, the PSTs merely indicated the need to increase the quantity of the work. Decisions such as these serve as additional obstacles in providing access to high-quality mathematics instruction. While most of the references (66.3\%) within access indicate actions that would benefit the student, such as providing more challenging work or including the student in advanced classes or grade levels, the remaining references either ignored Eric[a]'s mathematical needs (i.e., focusing on tutoring for literacy) or suggested providing one-on-one practice to make sure Eric[a] understood the mathematics.

Achievement Approximately 32\% of the PSTs' responses referred to addressing classroom management to further support the student's participation and outcomes. While classroom management was a component of each of the vignettes, actions such as separating the student 
or isolating Eric[a] from the rest of the mathematical community were more commonly referenced for the African American students. In fact, of the 51 responses in achievement, 27 of these were specific references to removing African American Eric[a] from the group (17 males and 10 females). One PST expressed that African American Eric's behavior was such an obstacle that he should not continue with his peers to the next grade level. This is alarming because although Eric was noted in the vignette to be above grade level in mathematics, PSTs inhibited his participation in appropriate mathematical opportunities by disregarding his academic aptitude and instead focused solely on his behavior.

In looking at differences among males and females, the only times the PSTs referenced they would have the student share their thinking was in reference to Erica, and this occurred twice as much for African American Erica because the PSTs wanted to ensure she had the correct understanding of the problem. One PST suggested, "I would have [African American] Erica share her strategies with the rest of the class since they are so different."

Identity In the third level of noticing, the PSTs identified positive roles and positions for the student that would encourage him or her to identify as a contributing member of the classroom community. While not all of the suggested roles and responsibilities corresponded to Eric[a]'s identified success in mathematics, the responses did encourage the student to take a more leadership role in the classroom. For example, one PST expressed,

I would make [African American] Eric the classroom leader and give him jobs to do around the classroom like having him turn the lights on and off and having him sharpen the pencils. This will make him feel more like he is a part of the classroom and hopefully it will make him more of a helper than someone who disrupts other students' work.

While references to African American Eric were the only ones that reflected roles and responsibilities that did not relate specifically to mathematics, references for African American Eric[a]'s leadership 
roles, like those for White Eric[a], regularly did involve offering roles to teach peers such as "pairing her up with a lower level math student," "allowing him to be the teacher," or inviting her "to be my special math scientist."

It was reassuring that the PSTs noticed the need to develop students' identities as mathematicians and positive members of the classroom culture by connecting with the student and providing systems of support. For example, one PST claimed, "students just want love and attention. This is why I think it is so important to create a caring community in the classroom. I truly believe that when students trust and feel loved and accepted, they will perform much better in school." Another PST stated, "I think the issues could be solved by just letting Erica know there is someone who cares." The PSTs also noticed the former abuse in Eric[a]'s past and recognized the student's stressful living situations can negatively impact a student and may be exhibited through defiant or inappropriate behavior. Consequently, several PSTs saw the need to create a place in which Eric would feel safe and secure. One PST articulated,

I think that the student is acting up because of his home life and I have seen this many times. Yes, you should have clear, set rules in class, but as an educator you should take the time to see where the student is coming from and maybe provide resources such as counseling.

Despite the PSTs' reference to develop a caring classroom environment for all students, the PSTs identified the need to have culturally relevant pedagogy for all of the students except White Eric. A larger number of these connections were made for White Erica - by mostly White female PSTs.

Power Several of the PSTs' responses focused on positive pedagogical practices such as mentoring or personally connecting with the student. For example, family discussions with the grandmother to glean ideas that would support Eric[a] had the greatest number of references within power, and providing a positive role model/ mentor was more focused on African American Eric. Moreover, recognizing the issues at home and considering referrals to the guidance counselor were 
also viewed as considering Eric[a]'s needs. Finally, putting a reward system in place that would provide positive reinforcement through praise and tokens was suggested by several PSTs. In each of these cases, these references were made more often for African American Eric[a], than for the White counterpart.

Despite these more positive interventions and instructional strategies, a large number of the PSTs' responses focused on "support" systems that could potentially disempower the student and cause Eric[a] to lose his/her voice in the classroom. Actions such as discrediting the student's voice by not allowing Eric[a] to solve the problem in the way that is both mathematically correct and makes sense to him/her were discouraging. For example, one PST explained that White Erica was only using this strategy to be defiant and more difficult. Responses like this are quite alarming because mathematics teacher educators not only want to prepare PSTs with a deep conceptual understanding of the mathematics but to also be prepared to accept multiple strategies as viable approaches to solving mathematical problems.

More worrisome is the disproportional distribution of these less beneficial practices for males and African American students. For example, none of the PSTs responses for African American Eric encouraged him to justify his mathematical thinking. In addition, the PSTs argued that the mathematical strategy Erica (both African American and White) used should align with the teacher's.

\section{Discussion}

We used the equity noticing framework to examine what PSTs attended to in a classroom vignette and how these observations, interpretations, and instructional decisions compared across race and sex. Because of the dichotomy the PSTs perceived of Eric[a], his/her mathematical knowledge and the disruptive behavior exhibited during the mathematics lesson, the responses to the vignette provided an opportunity to reveal hidden biases in PSTs' noticing.

The results of this study tell a very interesting tale of what PSTs noticed across the four dimensions of equity both within and among each level of noticing. Some of the most telling results included references to stereotypes within and across both race and sex. For example, 
when examining the referring responses by sex, a larger percentage of references were made when Erica shared her mathematical thinking, had the correct answer, and completed the problem as the teacher instructed, whereas a greater percentage of references for Eric corresponded to giving him "busy work" that was not cognitively demanding.

When examining disparities across race, the largest number of references across the four dimensions of equity and three levels of noticing is related to the African American students. For example, the PSTs attended to the African American students' achievement across all levels of noticing. This is particularly interesting because several references often indicated the PSTs' desire to remove the African American student from the classroom, which could result in the student falling behind due to lack of instruction. On the other hand, the PSTs' responses indicated they would remove White Eric[a] from his/her group but keep him/her in the classroom. The PSTs were more cognizant of and had more negative consequences for African American Eric[a]'s disruptive behavior. It was alarming that the PSTs stated African American Eric should be held back a grade level to learn appropriate behaviors.

Although the PSTs shared culturally relevant practices for the African American students, they were more adept to suggest culturally relevant strategies for White Erica. It was interesting that none of the responses related to culturally relevant pedagogy were for White Eric. This appears to indicate the PSTs did not think they needed to make explicit connections to White Eric's culture, which may be because White males are considered dominant in the Western society. Therefore, because of the privilege and dominance that exist for White males, cultural relevance is unnecessary because the connections are already being made for him.

Furthermore, the PSTs referenced all the students should be given a leadership role in the mathematics classroom. The leadership roles ascribed to African American Eric, however, were unrelated to mathematics, while the suggested leadership roles for the White students were directly and explicitly related to mathematics and mathematics instruction.

Finally, the PSTs alluded to the importance of the students having role models. This was more evident for African American Eric, which may indicate the stereotypical view that PSTs contend African 
American families lack male role models in the home. It is also interesting the PSTs did not state White Erica needed a role model or mentor. This could be because the PSTs may have viewed themselves as White Erica's role model since the majority of the PSTs were White females.

The results of this study provide an initial glimpse into what PSTs attend to, and through a comparative analysis of the demographic variation in the provided Eric[a] vignette, we documented how PSTs perceived issues of equity when a single classroom episode was represented where only the race and sex of the student were changed. Several results found in the study indicate distinct discrepancies - not only between races but also between males and females - which can be detrimental for particular populations if not explicitly and carefully addressed in teacher education programs.

The results from this study provide implications for mathematics teacher educators in that PSTs must have additional opportunities to discuss the impact of students' cultural identity and perceptions of themselves within the mathematics community as well as the resources, tasks, and tools that provide access to learn mathematics. Teachers cannot attend to everything that occurs in a classroom; thus they must make choices - whether consciously or subconsciously about what they notice. In several responses, the PSTs directly and explicitly identified the student as the sole source of the problem or disruption that was occurring in the mathematics classroom without critically reflecting on how the teacher's actions or home events potentially contributed to Eric[a]'s outbursts. From these responses, it was evident that a large proportion of the PSTs first noticed the behaviors - even without explicitly identifying them in their written responses - and wanted to "deal with" Eric[a]'s actions. While this attribution may be expected of PSTs, it is important that mathematics teacher educators help PSTs focus on what they are and are not attending to in their instruction that may cause students' disruptive behavior.

The data from Eric[a]'s vignette provides an opportunity for mathematics teacher educators to reflect on how equity issues are addressed in their mathematics methods courses. Moreover, the results may prompt teacher educators to consider how to design tasks and activities that purposefully and explicitly address equity in mathematics education by supporting productive actions, while simultaneously 
bringing awareness to and challenging PSTs' stereotypes, hidden biases, and unproductive beliefs about students from diverse backgrounds. In order to create opportunities that foreground an equity-centered approach to mathematics teaching and learning, we, as mathematics teacher educators, must recognize what PSTs attend to as they direct their attention to various classroom events and how what they notice relates the events to broader principles of teaching and learning.

\section{References}

Aguirre, J. M., Turner, E. E., Bartell, T. G., Kalinec-Craig, C., Foote, M. Q., Roth McDuffie, A., et al. (2012). Making connections in practice: How prospective elementary teachers connect to children's mathematical thinking and community funds of knowledge in mathematics instruction. Journal of Teacher Education, 64(2), 178-192.

Allsopp, D. H., Kyger, M. M., \& Lovin, L. H. (2007). Teaching mathematics meaningfully: Solutions for reaching struggling learners. Baltimore: Paul H. Brookes Publishing Co.

Averill, R., Anderson, D., Easton, H., Te Maro, P., Smith, D., \& Hynds, A. (2009). Culturally responsive teaching of mathematics: Three models from linked studies. Journal for Research in Mathematics Education, 4O(2), 157-186.

Ball, D. (2011). Forward. In M. G. Sherin, V. R. Jacobs, \& R. A. Philipp (Eds.), Mathematics teacher noticing: Seeing through teachers' eyes (pp. xx-xxiv). New York/London: Routledge.

Bartell, T. G. (2010). Learning to teach mathematics for social justice: Negotiating social justice and mathematical goals. Journal for Research in Mathematics Education, 41(1), 5-35.

Battey, D. (2013). "Good" mathematics teaching for students of color and those in poverty: The importance of relational interactions within instruction. Educational Studies in Mathematics, 82(1), 125-144.

Diversity in Mathematics Education Center for Learning and Teaching. (2007). Culture, race, power and mathematics education. In F. Lester (Ed.), Second handbook of research on mathematics teaching and learning (Vol. 2, pp. 843908). Reston, VA: National Council of Teachers of Mathematics.

Forgasz, H., \& Rivera, F. (Eds.). (2012). Towards equity in mathematics education: Gender, culture and diversity. New York: Springer.

Freitas, D. (2008). Troubling teacher identity: Preparing mathematics teachers to teach for diversity. Teaching Education, 19(1), 43-55.

Futrell, M. H., Gomez, J., \& Bedden, D. (2003). Teaching the children of a new America: The challenge of diversity. Phi Delta Kappan, 84(5), 381-385. 
Gay, G. (2000). Culturally responsive teaching: Theory, research, \& practice. New York: Teachers College Press.

Gutiérrez, R. (2002). Enabling the practice of mathematics teachers in context: Toward a new equity research agenda. Mathematical Thinking and Learning, 4(2\&3), 145-187.

Gutiérrez, R. (2007). (Re)defining equity: The importance of a critical perspective. In N. S. Nasir \& P. Cobb (Eds.), Improving access to mathematics: Diversity and equity in the classroom (pp. 37-50). New York: Teachers College Press.

Gutiérrez, R. (2009). Embracing the inherent tensions in teaching mathematics from an equity stance. Democracy and Education, 18(3), 9-15.

Gutiérrez, R. (2013). The sociopolitical turn in mathematics education. Journal for Research in Mathematics Education, 44(1), 37-68.

Gutstein, E. (2003). Teaching and learning mathematics for social justice in an urban, Latino school. Journal for Research in Mathematics Education, 34(1), 37-73.

Hand, V. (2012). Seeing power and culture in mathematics learning: Teacher noticing for equitable mathematics instruction. Educational Studies in Mathematics, 80(1), 233-247.

Hart, L. E. (2003). Some directions for research on equity and justice in mathematics education. In L. Burton (Ed.), Which way social justice in mathematics education? (pp. 27-49). Westport, CT: Praeger.

Hussar, W. J., \& Bailey, T. M. (2016). Projections of education statistics to 2023 (NCES 2015-073). U.S. Department of Education, National Center for Education Statistics. Washington, DC: U.S. Government Printing Office.

Irvine, J. (2003). Educating teachers for diversity. New York: Teachers College Press.

Jackson, C., \& Jong, C. (2017). Reading and reflecting: Elementary preservice teachers' conceptions about teaching mathematics for equity. Mathematics Teacher Education and Development, 19(1), 66-81.

Ladson-Billings, G. (1995). "But that's just good teaching!" The case for culturally relevant pedagogy. Theory Into Practice, 34(3), 159-165.

Lemons-Smith, S. (2008). Dr. Asa G. Hilliard III: Trumpeter for the academic and cultural excellence of African American children. Review of Educational Research, 78(4), 908-920.

Leonard, J., \& Martin, D. B. (Eds.). (2013). The brilliance of black children in mathematics: Beyond the numbers and toward new discourse. Charlotte, NC: Information Age.

Lubienski, S. T. (2002, April 1-5). Are we achieving "mathematical power for all?" A decade of national data on instruction and achievement. Paper presented at the Annual Meeting of the American Educational Research Association, New Orleans, LA.

Martin, D. (2003). Hidden assumptions and unaddressed questions in mathematics for all rhetoric. The Mathematics Educator, 13(2), 7-21. 
Matthews, L. E. (2005). Towards design of clarifying equity messages in mathematics reform. The High School Journal, 88(4), 46-58.

McCulloch, A. W., Marshall, P. L., \& DeCuir-Gunby, J. T. (2009). Cultural capital in children's number representations. Teaching Children Mathematics, 16(3), 184-189.

McGuire, M. (2006). Cooperative learning training materials. Columbia, MO: Micki McGuire.

National Center of Educational Statistics. (2010). 2010 condition of education. Washington, DC: Department of Education.

National Council of Teachers of Mathematics. (2000). Principles and standards for school mathematics. Reston, VA: Authors.

National Council of Teachers of Mathematics. (2014). Principles to actions: Ensuring mathematical success for all. Reston, VA: Authors.

Olson, I. R., \& Marshuetz, C. (2005). Facial attractiveness is appraised in a glance. Emotion, 5(4), 498-502.

Pinnow, R., \& Chval, K. B. (2014). Positioning ELLs to develop academic, communicative, and social competencies in mathematics. In M. Civil \& E. Turner (Eds.), The common core state standards in mathematics for English language learners: Grades K-8 (pp. 72-95). Alexandria, VA: TESOL Press.

Rousseau, C., \& Tate, W. F. (2003). No time like the present: Reflecting on equity in school mathematics. Theory Into Practice, 42(3), 210-216.

Sherin, M. G., Russ, R. S., Sherin, B. L., \& Colestock, A. (2009). Professional vision in action: An exploratory study. Issues in Teacher Education, 17(2), 27-46.

Sleeter, C. E. (2001). Preparing teachers for culturally diverse schools: Research and the over-whelming presence of whiteness. Journal of Teacher Education, 52(2), 94-106.

Turner, E. E., \& Drake, C. (2016). A review of research on prospective teachers' learning about children's mathematical thinking and cultural funds of knowledge. Journal of Teacher Education, 67(1), 32-46.

Turner, E. E., Drake, C., Roth McDuffie, A., Aguirre, J., Bartell, T. G., \& Foote, M. Q. (2012). Promoting equity in mathematics teacher education: A framework for advancing teacher learning of children's multiple mathematics knowledge bases. Journal of Mathematics Teacher Education, 15(1), 67-82.

Ukpokodu, O. M. (2011). How do I teach mathematics in a culturally responsive way? Identifying empowering teaching practices. Multicultural Education, 18(3), 47-56.

van Es, B., \& Sherin, M. G. (2002). Learning to notice: Scaffolding new teachers' interpretations of classroom interactions. Journal of Technology and Teacher Education, 10(4), 571-596.

van Es, E. A., \& Sherin, M. G. (2006). How different video club designs support teachers in "learning to notice". Journal of Computing in Teacher Education, $22(4), 125-136$.

van Es, E. A., \& Sherin, M. G. (2010). The influence of video clubs on teachers' thinking and practice. Journal of Mathematics Teacher Education, 13(2), $155^{-176 .}$ 
Vomvoridi-Ivanović, E., \& Chval, K. B. (2014). Challenging beliefs and developing knowledge in relation to teaching English language learners: Examples from mathematics teacher education. In B. Cruz, C. Ellerbrock, A. Vasquez, \& E. Howes (Eds.), Talking diversity with teachers and teacher educators (pp. 115130). New York: Teacher's College Press.

Wager, A. A. (2014). Noticing children's participation: Insights into teacher positionality toward equitable mathematics pedagogy. Journal of Research in Mathematics Education, 45(3), 312-350.

Watson, D., Charner-Laird, M., Kirkpatrick, C. L., Szczesiul, S. A., \& Gordon, P. (2006). Effective teaching/effective urban teaching: Grappling with definitions, grappling with difference. Journal of Teacher Education, 57(4), 395-409. 